\title{
Coulisses
}

Revue de théâtre

7 | Printemps 1993

Varia

\section{Léonce et Léna, produit par le Théâtre National de la Communauté Française de Belgique}

Gérard Jugan

\section{(2) OpenEdition}

1 Journals

Édition électronique

URL : http://journals.openedition.org/coulisses/2230

DOI : $10.4000 /$ coulisses.2230

ISSN : 2546-9460

Éditeur

Presses universitaires de Franche-Comté

Édition imprimée

Date de publication : 1 avril 1993

Pagination : 31

ISSN : 1150-594X

\section{Référence électronique}

Gérard Jugan, «Léonce et Léna, produit par le Théâtre National de la Communauté Française de

Belgique », Coulisses [En ligne], 7 | Printemps 1993, mis en ligne le 15 mars 2019, consulté le 29

octobre 2019. URL : http://journals.openedition.org/coulisses/2230 ; DOI : 10.4000/coulisses.2230

Ce document a été généré automatiquement le 29 octobre 2019.

Coulisses 


\title{
Léonce et Léna, produit par le Théâtre National de la Communauté Française de Belgique
}

\author{
Gérard Jugan
}

Le Théâtre National de la Communauté française de Belgique, invité par le C.D.N. et l'Espace Scène Planoise de Besançon, a présenté du 17 au 19 décembre 1992 Léonce et Léna de Georg Büchner.

La mise en scène de la pièce, remarquable à bien des égards, illustre cependant de manière exemplaire à quel point cette "comédie ", en dépit des apparences, est une œuvre difficile à manier.

\section{Un travail rigoureux}

1 Le spectacle est à coup sûr le fruit d'un travail rigoureux sur le texte qu'il s'attache manifestement à respecter: tout d'abord parce qu'il le donne intégralement, sans procéder à un découpage arbitraire, parce qu'il évite aussi de l'estomper derrière une théâtralité bavarde, telle qu'on la rencontre souvent aujourd'hui, quand le spectateur « voit » plus qu'il « n'entend », l'image scénique étant incapable de rejoindre le texte de l'œuvre.

2 Un dispositif ingénieux (un escalier double, à trois niveaux) permettait une articulation claire de l'action: aucune bousculade sur la scène, mais en permanence une canalisation sans équivoque de l'attention du spectateur.

Un décor simple et esthétique jouant sur une stylisation décorative à base de motifs géométriques, dans de jolies couleurs chaudes, habilement exploitée par des éclairages significatifs (en particulier au moment où Léonce et Léna se rencontrent sur la route de l'Italie, sous un ciel lumineux, irréel, parfaitement en accord avec l'atmosphère poétique, un peu magique de la scène). Des rôles bien distribués, avec des acteurs exprimant clairement leur position dans la logique de la pièce: d'une part des fantoches et leurs victimes : le roi, les notables, les paysans - ils excellaient à suggérer 
l'agitation ridicule et vaine, la cruauté de la comédie du pouvoir, à faire passer le comique délétère de la pièce - de l'autre les personnages "vivants", chargés de formuler les problèmes qu'elle pose, en priorité le couple Léonce-Valério, un peu déséquilibré cependant par la vitalité et la remarquable présence de ce dernier, à laquelle le comédien interprétant Léonce, n'était pas toujours capable de donner la réplique.

4 Et pourtant, malgré la conjonction de tous ces éléments, malgré le travail très méticuleux et l'ingéniosité de cette troupe et de son metteur en scène et leur profond respect pour l'œuvre de Büchner, il manquait à ce spectacle quelque chose qui lui aurait permis d'être encore plus convaincant: ce qu'on pourrait appeler une sorte d'élan intérieur, susceptible, depuis le début jusqu'à la fin d'emporter l'adhésion du public, de le faire vibrer avec Léonce et Léna.

\section{Un spectacle sur papier glacé}

On ne peut reprocher à la mise en scène d'être statique, bien au contraire, mais le spectateur était convié à tourner les pages d'un bel album très bien composé; il restait un peu à l'écart de l'aventure de Léonce, c'est-à-dire d'un être qui a beaucoup de mal à vivre, qui est obsédé par la mort et qui, peu à peu, au fil des scènes, s'arrache à sa morbidité grâce à Valério et Léna. Ce voyage est sans doute l'âme de la pièce et ne pas y associer étroitement le spectateur, ne pas l'entraîner à le partager, en lui faisant entendre clairement, d'abord la désespérance et puis l'éveil de l'espoir, compromet l'efficacité de cette « comédie » qui est, en réalité, éminemment dramatique.

On ne le sentait pas assez au commencement, quand Léonce dit son mal de vivre, quand Rosetta chante qu'elle a la mort dans l'âme, quand Léna le chante également, quand les deux amants veulent mourir et que Léonce tente de le faire : toute cette pièce dans la pièce n'était pas assez vigoureusement exprimée. A un moment, cependant, la mise en scène fit entendre l'âpreté de la voix de Büchner, l'âpreté de la souffrance et de la révolte : au moment où Valério, changeant brusquement de visage et de voix " casse " la comédie pour dénoncer durement, dans un long réquisitoire, l'homme-marionnette.

7 Büchner a multiplié à plaisir dans sa pièce les masques et les jeux de miroirs; ils rendent la mise en scène périlleuse et peuvent la faire hésiter entre plusieurs directions qui désorientent le spectateur. Le spectacle très soigné du Théâtre National de la communauté française de Belgique aurait pu être aussi, en insistant sur certains passages névralgiques de l'œuvre, un spectacle profondément émouvant.

\section{AUTEURS}

\section{GÉRARD JUGAN}

Maître de conférences de Littérature allemande à l'Université de Franche-Comté, il est l'auteur de plusieurs articles sur le théâtre allemand. 